\title{
Las ideas filosóficas de Sor Juana Inés de la Cruz
}

\author{
Luis ARMando GonzÁleZ
}

Su erudición... junto con su bermosura... no podía Dios enviar azote mayor a aqueste reino".

ANTONio Núñez de Miranda, CONFESOR DE SOR JUANa INÉS DE LA CRUZ

Temo que no sea posible comprender lo que nos dicen su obra y su vida si antes no asimos el sentido de su renuncia a la palabra.

Octavio Paz

\section{Sor Juana: ¿filosofa latinoamericana?}

Este ensayo se debió haber titulado Sor Juana Inés de la Cruz, primera filósofa latinoamericana'. Y ello por dos razones, al menos: ante todo, porque la obra poética de Sor Juana Inés de la Cruz (16511695) - cuyos méritos han sido de sobra reconocidos en diferentes momentos y por distintos críticos literarios- no fue ajena a las preocupaciones filosóficas consideradas en sentido estricto; y, en segundo lugar, porque, hasta donde se tiene noticia, fue la primera mujer latinoamericana que hizo una elaboración filosófica con creatividad y con plena conciencia de lo que hacía, aunque para ello se valiera del instrumento que mejor dominaba, esto es, el discurso poético. 
Sor Juana fue una poeta, pero también fue una filósofa, esto último no por haberse graduado o haber sido una profesional de la filosofía, sino por haber filosofado con rigor y dominio de los temas y problemas filosóficos que acuciaban a los hombres y mujeres de su época.

Aunque hay suficientes razones para llamarla la "primera filósofa latinoamericana", no sería extraño que tal denominación cause resquemores en quienes, por un lado, objetarán su condición de latinoamericana; y en quienes, por otro, objetarán su condición de filósofa. Los primeros recurrirán al argumento de que Sor Juana era un criolla, una hija de españoles nacida en Nueva España (México), y que, por lo tanto, no era resultado del mestizaje que muchos consideran característico de lo latinoamericano. Aquí se estaría enfatizando lo racial como rasgo definitorio de las identidades individuales -en este caso, de la identidad de Sor Juana-. Sin embargo, desde hace bastante tiempo se han descartado, por ser sociológica e históricamente infundadas, las concepciones que hacen de la raza lo determinante de la identidad ${ }^{2}$.

Ahora se sabe que las identidades individuales y colectivas, más que de la raza, se nutren de las prácticas, los sueños, las esperanzas, frustraciones y tradiciones que individuos y grupos asumen como propias en un momento dado de su historia particular, sin que ello signifique la negación de las prácticas, sueños, esperanzas, frustraciones y tradiciones de otros individuos y pueblos. Es decir, las identidades son, además de cambiantes en el tiempo - como dicen los especialistas, no son una esencia inmutable - , una mezcla de tradiciones, modos de ser y prácticas, mezcla tanto más rica cuanto más son las fuentes culturales de las que abreva.

Étnicamente, Sor Juana es una criolla, pero su anclaje vital -l horizonte de su vida, sus expectativas, sueños y frustraciones- está en el mundo americano, con los problemas concretos, culturales, sociales, religiosos, políticos y económicos de la época. Como otros criollos, sus referentes intelectuales son los que ha adquirido a partir de las corrientes intelectuales en que fue educada; esas corrientes intelectuales no eran ajenas ni a los problemas de España del momento ni a la tradición cultural española, en la que confluían la neoescolástica, el hermetismo, el neoplatonismo, el humanismo renacentista, las primeras corrientes científicas modernas, y la ciencia y el arte árabes ${ }^{3}$. 
Vitalmente, Sor Juana es una mexicana y por extensión una latinoamericana. Su criollismo, más que racial, era expresión de uno de los modos de ser latinoamericano en la Nueva España del siglo XVII: además de abrir las puertas hacia las esferas más importantes del poder cultural, económico y político, era una matriz existencial, esto es, una forma de ver la vida, de soñar y de sentir que, sin ser ajena a los modos de ser españoles, intentaba demarcarse de ellos. No hay que olvidar que el primer nacionalismo que se conoció en América hispanohablante fue el nacionalismo criollo, fuertemente cargado de acentos patrióticos: amor a la patria como tierra, como geografía y territorio. Y ello justamente como parte de un esfuerzo por reconocerse y ser reconocidos por los peninsulares como los auténticos creadores de la prosperidad y la riqueza americanas, es decir, como los auténticos propietarios de la tierra que sus padres -los conquistadores- les habían heredado y en la que ellos habían nacido. "El inventario de las riquezas naturales -dice Enrique Florescano-, el crecimiento de las ciudades, o los adelantos en la extracción minera, la circulación de mercancías y el desarrollo de las artesanías e industrias adquirieron la cualidad de pruebas irrefutables del destino grandioso que la Providencia le había señalado a la patria criolla"'.

En segundo lugar, no faltará quien objete la condición de filósofa de Sor Juana, esgrimiendo su condición de poeta. Esta forma de ver las cosas hace honor a un prejuicio del cual no están exentos algunos de los más connotados historiadores de la filosofía latinoamericana, el cual consiste en sólo considerar como filósofos a aquellos pensadores que expresamente se dedicaron a la filosofía o que cursaron estudios académicos y se graduaron como filósofos. A partir de esta consideración, los que así piensan muestran extrañeza cuando se sugiere que autores no dedicados profesional y expresamente a la filosofía han hecho aportes significativos a ella.

En virtud de ese prejuicio, autores importantes para la filosofía latinoamericana, pero no filósofos de profesión, como la misma Sor Juana Inés de la Cruz, Octavio Paz ${ }^{5}$ o Alfonso Reyes ${ }^{6}$ - sólo para mencionar a tres de los grandes talentos literarios de América Latina-, son dejados de lado, sin reparar en que en escritos importantes suyos hay hondas reflexiones filosóficas -y no sólo intuiciones-, mucho más originales que las que se encuentran en la producción de un buen número de profesionales de la filosofía. 
Lo anterior explica por qué a Sor Juana -al igual que a Paz o a Reyes- no se le ve con naturalidad como, además de poética y literaria, una personalidad filosófica. Sin embargo, este reconocimiento se hace cada vez más necesario, pues en Sor Juana sí hay una elaboración filosófica que no sólo refleja el dominio de una tradición filosófica particular, sino el esfuerzo por trascender -o por lo menos de mostrar los límites de- esa tradición. Su condición de poeta no debe ser óbice para obviar o no reconocer su específica contribución al pensamiento filosófico latinoamericano. Su aporte obliga a los historiadores de la filosofía latinoamericana a reconocer que el debate filosófico de la región se ha nutrido de reflexiones realizadas, entre otros, por poetas de primera categoría y que esas reflexiones no han sido de menor calidad, profundidad y originalidad que las realizadas por filósofos también de primera categoría.

El menosprecio con el que muchos filósofos profesionales y no pocos historiadores de la filosofía han visto a poetas como Sor Juana -y la cara de sorpresa que han puesto cuando un colega les ha sugerido que en ella hay un aporte filosófico importante-, deben ceder su paso, no a la condescendencia, sino al respeto y al reconocimiento de su aporte en lo que tiene de original y creativo. Por cierto, algunas mentes ilustres comenzaron a dar pasos en esta dirección, por los menos desde 1950.

Precisamente, en ese año Francisco López Cámara escribió su artículo "El cartesianismo en Sor Juana y Sigüenza y Góngora”, en lo que fue un primer esfuerzo por recuperar a Sor Juana como filósofa'. En 1963, Rafael Moreno escribió "La filosofía en la Nueva España", una de cuyas tesis principales es que en el siglo XVII los pensadores novohispanos se ocuparon de temas estériles y de disputas interminables, es decir, que se trató de un escolasticismo decadente. Sin embargo, Moreno valoriza a Sor Juana y a Sigüenza y Góngora, a quienes convierte -según señala Ignacio Osorio- “en grandes heterodoxos que rompen el pensamiento tradicional; se les enviste de señeros precursores de la cultura moderna que introducirán los jesuitas; precursores, por otra parte, que no tienen continuadores inmediatos"8.

Para Rafael Moreno -continua Osorio-, después de Sor Juana y Sigüenza y Góngora, “se abre un 'hiatus de medio siglo' durante el cual presenciamos las vacilaciones entre lo escolástico y la generación del medio siglo del XVIII que, para Moreno, marcará la transición 
entre tradición y modernidad"'. En 1960, José Gaos escribe su artículo "Un sueño de un sueño", en el cual reivindica con contundencia el aporte filosófico de Sor Juana en su poema "Primero sueño". En 1982, Octavio Paz, en su obra Sor Juana Inés de la Cruz o las trampas de la $f e$, hace un análisis pormenorizado de "Primero sueño" y desentraña sus claves filosóficas ${ }^{10}$. Por último, en 1984, Elías Trabulse, examina, en su trabajo "El hermetismo de Sor Juana Inés de la Cruz", las resonancias herméticas presentes en el pensamiento de la monja mexicana.

Más adelante, cuando nos ocupemos del poema "Primero sueño", volveremos sobre las tesis de José Gaos y Octavio Paz. De momento, sólo nos interesa dejar establecido que el reconocimiento del talante filosófico de Sor Juana no es algo descabellado o un invento de última hora, sino que tiene antecedentes bien cimentados en la cultura intelectual latinoamericana. Si bien es cierto que las voces de quienes han rescatado para la filosofía a Sor Juana no son masivas, no es menos cierto que son voces sumamente cualificadas, que se han esforzado por ofrecer razones de peso para que la recepción intelectual de la monja mexicana vaya más allá del reconocimiento de sus inapreciables dotes como poeta.

Obviamente, sobrarán quienes recurran siempre, o bien a los orígenes criollos de Sor Juana, o bien a su carácter de poeta, para impedir que ocupe el lugar que le corresponde en la historia de la filosofía latinoamericana. Motivos semejantes proclamarán para excluir a Octavio Paz y a Alfonso Reyes. Pero ni Sor Juana, ni Paz, ni Reyes perderán con ello un ápice de su condición de pensadores de primer nivel; quienes saldrán perdiendo serán las nuevas generaciones de filósofos latinoamericanos -al igual que han salido perdiendo quienes entre sus mayores se niegan dialogar filosóficamente con Sor Juana, Paz o Reyes-, que no podrán ni reconocerse en la herencia que ellos representan ni podrán aprender de ellos ni dialogar con ellos.

Dicho lo anterior, es oportuno pasar al examen de las ideas filosóficas de Sor Juana. Sin embargo, previamente, se impone una somera aproximación a su biografía, así como al contexto histórico en el cual ella se desenvolvió. Porque, como señala Octavio Paz, "el enigma de Sor Juana Inés de la Cruz es muchos enigmas: los de la vida y los de la obra. Es claro que hay una relación entre la vida y la obra de un escritor pero esa relación nunca es simple. La vida no explica entera- 
mente la obra y la obra tampoco explica la vida... Entre la vida y la obra encontramos un tercer término: la sociedad, la historia. Sor Juana es una individualidad poderosa y su obra posee una indudable singularidad; al mismo tiempo, la mujer y sus poemas, la monja y la intelectual, se insertan en una sociedad: Nueva España, al final del siglo XVII" ${ }^{\prime 1}$.

\section{Sor Juana: su vida, su obra y su mundo}

Nacida en 1648 en Nepantla (México), Sor Juana -según cuentan sus biógrafos- fue una hija natural, fruto de la unión de Pedro Manuel de Asbaje e Isabel Ramírez, el primero posiblemente un caballero vizcaíno y la segunda hija de una familia criolla. Antes de ingresar a la orden de las jerónimas — cuando contaba con 21 años- Sor Juana utilizó su apellido materno, es decir, fue conocida como Juana Inés Ramírez. "La familia maternal de Juana Inés - dice Octavio Pazera criolla por los cuatro costados y criollos fueron su padrastro, los maridos de sus hermanas y la mujer de su medio hermano"'2. Este criollismo forjó la identidad de Sor Juana, al igual que su condición de hija natural, en una sociedad en la cual los hijos fuera de matrimonio, aunque fueran criollos, tenían enormes dificultades para triunfar, aunque, como apunta Paz, la condición de hijo natural no constituía en la época una escandalosa excepción. Además, Sor Juana era mujer, lo cual añadía una dificultad adicional a su vida. Con todo, tuvo una ventaja que seguramente no tuvieron otras mujeres en su misma situación: se crió en un ambiente familiar dominado por mujeres.

En efecto, a la muerte de su abuelo materno, en 1655, cuando Juana Inés contaba apenas con 7 años, la hacienda de Panoayán quedó en manos de su madre durante más 30 años". "Manejar una hacienda no era, ni es - comenta Paz- cosa fácil; aparte de exigir considerable rigor físico y resistencia de cuerpo y ánimo, requiere habilidad, tenacidad y don de mando. El hacendado no es únicamente el dueño de la tierra, los animales y los instrumentos de labranza: es el jefe de una comunidad. En esa familia de varonas, Juana Inés no fue una excepción"14.

A Juana Inés, pues, no le faltaron en su ambiente familiar los estímulos propicios para forjar un carácter fuerte, disciplinado y emprendedor. Tampoco le faltaron los estímulos intelectuales: en su familia abundaron los militares, los clérigos y los intelectuales. Diego Ruiz

Realldad 98, 2004 
Lozano -el medio hermano de Sor Juana- "fue capitán de lanceros y su hijo, el Mozo, también siguió la carrera de las armas y fue capitán del mismo cuerpo... Una media hermana de la poetisa, Doña Inés Ruiz Lozano, fue esposa de José Miguel Torres, secretario de la Universidad y poeta de cierto renombre. Uno de los hijos de ese matrimonio, José Diego de Torres, fue igualmente secretario de la Universidad y poeta como su padre y su tía. Otro de los Torres -el mercedario fray Miguel de Torres- fue familiar y biógrafo del Obispo de Puebla, el amigo y protector de Sor Juana, Manuel Fernández de Santa Cruz ${ }^{15}$.

Tampoco le faltaron las amistades importantes. Su fama de niña prodigiosa, que lee días enteros y recita poemas, se extiende hasta llegar a la corte virreinal. En $1664^{16}$, es invitada a la corte por la virreina Leonor Carreto, quien la convierte en una de sus damas de palacio. "Relación de superior a inferior - dice Paz-, de protectora a protegida, pero en la que estaba presente también el reconocimiento del valor de una joven excepcional. Es indudable que los dones intelectuales de Juana Inés impresionaron a la virreina no menos vivamente que su belleza"1'. Aunque la relación de mutua simpatía fue con ambos virreyes - Leonor Carreto y su esposo, Don Antonio Sebastián de Toledo, marqués de Mancera-, Juana Inés tuvo un fuerte apego con la virreina - dando pie a lo que Paz llamó una "amistad amorosa"- Entre los 16 y los 20 años, Juana Inés vivió en la corte de los Mancera; aprendió los usos y costumbres cortesanos, tal como los mismos se vivían en la Nueva España del siglo XVII. Su presencia en la corte fue un éxito; su ingenio poético y sus conocimientos filosóficos provocaron la admiración de cuantos participaban en las tertulias cortesanas, en las cuales Juana Inés fue en más de una ocasión el centro de atención ${ }^{18}$. Según cuenta Octavio Paz, justo cuando comenzaba a alcanzar renombre en la corte, decide, a los 19 años, hacerse novicia con las Carmelitas descalzas, pero esa experiencia la duró apenas tres meses, pues no pudo con la dureza de la regla carmelitana. Volvió a lo mundano, pero sólo por un tiempo: un año y medio después, cuando iba a cumplir 21 años, se integró para siempre a otra orden, más laxa en su disciplina, la de las jerónimas.

¿Por qué de esta decisión de Juana Inés? Octavio Paz descarta las dos tesis que usualmente se han sugerido: 1) que Juana Inés trataba de superar una crisis amorosa de carácter lésbico, precisamente con la 
virreina. Quienes se apuntan a esta tesis, aducen como prueba los poemas amorosos y eróticos de Juana Inés. $\mathrm{Y}$ a ellos, les responde Paz: "la poesía de la época no es una poesía confesional. La sinceridad era un valor para los románticos y lo es para los modernos; no lo fue para los poetas del siglo XVII. La poesía barroca presenta al lector esquemas arquetípicos del amor y de las pasiones, pero el lector no debe ni puede inferir que esos textos poseen un valor confesional"19. 2) Juana Inés hizo su opción religiosa por vocación, es decir, por un "llamado" de Dios. A quienes sostienen esta interpretación -muchos de ellos católicos-, Paz les recuerda que, aunque Juana Inés era una católica sincera, en la época "los conventos estaban llenos de mujeres que habían tomado un hábito no por seguir el llamado divino, sino por consideraciones y necesidad mundanas... La vida religiosa, en el siglo XVII, era una profesión... El convento era una acomodo. Pero no todas podían profesar: para abrazar la vida monástica había que tener una dote y pertenecer a una familia conocida"20.

Con Juana Inés - sugiere Paz-, las cosas no fueron tan distintas. $Y$, pese a ser bastarda y no tener fortuna, la ayuda de los virreyes y del confesor de éstos, el jesuita Antonio Núñez de Miranda, fue decisiva para que pudiera entrar al Convento de San Jerónimo, donde permaneció durante 26 años. Así pues, en un primer momento, "la elección de Juana Inés no fue el resultado de una crisis espiritual ni de un desengaño sentimental. Fue una decisión sensata, consecuente con la moral de la época y con los usos y convicciones de su clase. El convento no era escala hacia Dios sino refugio de una mujer que estaba sola en el mundo"21. En segundo lugar, estaba su amor al saber. "Desde el principio -escribe Paz-, desde los años en que leía a escondidas los libros de su abuelo, obraron en ella la transposición y la transmutación de sus inclinaciones: el amor al saber es la otra cara, la positiva, de su negación al matrimonio. No quiere casarse porque quiere saber. Quiere al saber... para saber, hay que ser hombre o parecerlo. La idea de disfrazarse de hombre, cortarse el pelo y, en fin, neutralizar su sexualidad bajo el hábito monjil, son sublimaciones o, más bien, traducciones de su deseo: quiere apoderarse de los valores masculinos porque quiere ser como un hombre"22. Ser como un hombre para saber: este el desafío que hace suyo Inés de la Cruz. Pero no es hombre, sino mujer. Esto - comenta Paz- la hace a fin de cuen- 
tas volverse contra los hombres, defender a las mujeres y anticipar el feminismo moderno ${ }^{23}$.

El convento le ofrece la oportunidad de dar concreción a su amor al conocimiento, pero también a su deseo de ser conocida. Tuvo la suerte de estar en un convento donde se respiraba bastante libertad: "la regla era blanda y las infracciones numerosas y generales" -escribe Paz-. Y continúa: "ella no fue una excepción: fue una monja tibia y no se distinguió ni por el fervor ni por el rigor"24. Ese relajamiento permitió a Sor Juana mantener un contacto con el mundo exterior, especialmente con la corte virreinal. Tuvo una buena relación con fray Payo Enríquez de Rivera, quien siendo Arzobispo de México fue nombrado Virrey en 1673. Esta amistad le dio mayor libertad a Sor Juana dentro del convento. Fray Payo fue sucedido, en 1680 , por Tomás Antonio de la Cerda, Marqués de la Laguna. Con este virrey, pero especialmente con su esposa - María Luisa Manrique de Lara y Gonzaga, condesa de Paredes-, Sor Juana estableció una relación estrecha y afectivamente intensa, además de productiva desde el punto de vista intelectual y poético.

María Luisa tenía fama de hermosa y, a juzgar por los poemas de Sor Juana, lo fue en extremo. También debe haber sido discreta, sensible e inteligente pues de otra manera sería inexplicable su admiración por Sor Juana y el apasionado interés que mostró por sus escritos. Además de ser la inspiradora de muchos de sus poemas, la incitó a que escribiese uno de sus mejores: El divino Narciso. También se debe a la condesa, como es sabido, la publicación del primer volumen de Sor Juana: Inundación castálida ${ }^{25}$. Al último virrey que Sor Juana pudo conocer fue a Gaspar de Sandoval Cerda Silva y Mendoza, conde de Galve, quien asumió el cargo en 1688 y lo dejó en 1696. "La poesía cortesana de Sor Juana durante el virreinato del conde de Galve cumplió la misma función social y simbólica de la escrita bajo los otros virreyes: ser un ritual político, una alegoría de las relaciones ideales entre el señor y sus vasallos. Al mismo tiempo, sor Juana se apoyaba en el favor del palacio para afirmar su posición en el convento y conservar su independencia frente a las otras monjas. Gracias al prestigio y a la influencia que le otorgaron sus poemas cortesanos, pudo defenderse de las envidias, mezquindades e intrigas de la vida conventual"26. 
Sor Juana se sirvió del convento para conocer y de sus relaciones con los virreyes para que su conocimiento fuera divulgado y discutido. Su producción escrita -ciertamente abundante ${ }^{27}$ tiene mucho de oportunismo, pero ese oportunismo -escribir poemas de ocasión, por ejemplo- es el costo a pagar para poder escribir y decir lo que le gusta e inquieta. "La avidez de Sor Juana por la comunicación escrita -señala Paz- revela cierto oportunismo, un ansia inmoderada por conocer y ser conocida. Vanidad, sí, pero asimismo soledad. Ahogo, asfixia: le quedaba chico no sólo el convento, sino el país. Y más: su mundo. Sus verdaderos contemporáneos no estaban ni en Madrid ni en Lima ni en México, sino en aquella Europa de fines del siglo XVII que se preparaba a inaugurar la era moderna y a la que España había dado la espalda"28.

La pequeñez de su mundo -la Nueva España de su época- se le revela tal cual cuando, en 1690, publica su Carta Atenagórica -una crítica al famoso sermón del jesuita Antonio de Vieyra sobre las “finezas de Cristo"-, que le vale una fuerte reprensión del Obispo de Puebla, Manuel Fernández de Santa Cruz, quien prácticamente le ordena guardar silencio, en su Carta de Sor Filotea de la Cruz. Sor Juana, en su Respuesta a Sor Filotea de la Cruz, no sólo defiende su derecho a saber, sino que anuncia su sumisión a la autoridad eclesial.

¿Cómo era ese mundo en el que le tocó vivir a Sor Juana Inés de la Cruz? No está por demás insistir en la peculiaridad del orden colonial, es decir, en los vínculos de América con España y en el estatus de los habitantes del Nuevo Mundo. Eran, al igual que sucedía con los habitantes de la península, súbditos del rey, es decir, tenían los mismos derechos y obligaciones que ellos. También hay que recordar que la época colonial se extiende aproximadamente desde 1600 hasta 1800. Y en este lapso de tiempo se generan una serie de hábitos culturales que todavía encuentran eco en nuestro tiempo y que por ello merecen un examen particular. Octavio Paz no sólo ha llamado la atención sobre la importancia de la religiosidad colonial -porque nos muestra "el sentido de nuestra cultura y el origen de muchos de nuestros conflictos posteriores ${ }^{n}$-, sino que elaboró un penetrante análisis tanto de la religión y la Iglesia en la Colonia como de la vida cultural de la época. Estos análisis encontraron su mejor expresión en dos de sus obras fundamentales: Sor Juana Inés de la Cruz o las trampas de la $f e$, libro al que ya hemos hecho referencia en este ensayo, y El labe- 
rinto de la soledad (1950), en el que aborda el problema de la identidad del mexicano, "no como una esencia -escribe $\mathrm{Paz}$-, sino como una historia".

Para comenzar, según Octavio Paz, uno de los focos culturales durante la época colonial son la Iglesia y la Universidad, vistas ambas como los depósitos exclusivos del saber más elaborado (filosofía-ciencia). Fuera de estos recintos no hay forma de estar al tanto del conocimiento especializado. Asimismo, lo que se diga en la universidad y la iglesia no puede ser dejado de lado, pues ambas gozan de autoridad intelectual. ¿Cuál es la cultura que emana de la Iglesia y la Universidad? Emana una cultura docta y para doctos, cuya mejor formulación debe ser en latín. En segundo lugar, una cultura de élites, pues sólo los más ricos y más educados pueden acceder a ella. En tercer lugar, una cultura formadora de élites, pues quienes logran cumplir sus exigencias están llamados a tener una incidencia intelectual y política. En cuarto lugar, una cultura para españoles y para criollos: los mestizos y los indios no tienen acceso a ella. En quinto lugar, una cultura centrada en la teología, que es considerada la culminación del saber. Finalmente, una cultura encerrada sobre sí misma, sin vínculos con otras corrientes intelectuales europeas o con aportes más nativos, es decir, una cultura estancada y rígida.

"Nueva España — dice Paz- fue una sociedad culta: no sólo vivió con plenitud la cultura hispánica - la religión, el arte, la moral y los usos, los mitos y los ritos- sino que la adaptó con gran originalidad a las condiciones del suelo americano y la modificó sustancialmente. Pero en el sentido más limitado de la palabra — colindante con instrucción: producción y comunicación de novedades intelectuales, artísticas y filosóficas - sólo una minoría de la población podía llamarse culta; quiero decir: sólo una minoría tenía acceso a las dos grandes instituciones educativas de la época, la Iglesia y la Universidad. De esta circunstancia proviene otra característica: encerrada en las academias, universidades y seminarios religiosos, la cultura de Nueva España era una cultura docta y para doctos... La teología era la reina de las ciencias y en torno a ella se ordenaba el saber. Otra nota distintiva era la fusión de la tradición cristiana y el humanismo clásico: la Biblia y Ovidio, San Agustín y Cicerón, Santa Catarina y la sibila Eritrea"29.

Además de la Iglesia y la Universidad, el otro foco cultural es la corte, es decir, el espacio que se crea en torno a los funcionarios 
superiores de la corona (los virreyes) y que se presta a tertulias, cotilleos, romances y comentarios "liberales" acerca de los tópicos más diversos. La corte rivaliza con la iglesia y la universidad, en tanto que se presta al debate de cosas menos profundas: arte, pintura, literatura y filosofía, pero esta última no con los cánones universitarios o clericales. La corte tiene su propio lenguaje, estilos de comportamiento, actitudes y preocupaciones. También tiene su propia literatura, la literatura hermética, que se presta a la experimentación con nuevos estilos y a la innovación. La corte, además de "teatro de actividades sociales y culturales no menos que de intrigas y decisiones políticas... fue un centro de irradiación moral, literaria y estética; al influir en las actitudes de la gente, modificó profundamente la vida social y los destinos individuales... La corte virreinal ejerció una doble misión civilizadora: transmitió a la sociedad novohispana los modelos de la cultura aristocrática europea y propuso a la imitación colectiva un tipo de sociabilidad distinto a los que ofrecían las otras dos grandes instituciones novohispananas, la Iglesia y la Universidad. Frente a estas, la corte representa un modo de vida más estético y vital. La corte es el mundo, el siglo: un ballet no siempre vano y muchas veces dramático, en el que los verdaderos personajes son las pasiones humanas, de la sensualidad a la ambición, movidas por una geometría estricta y elegante" 30 .

Pese a sus desencuentros, ambos focos culturales son minoritarios, académicos, profundamente religiosos y dogmáticos (más el universitario y clerical que el cortesano). Asimismo, ambos estilos culturales son dominados por los hombres, porque la cultura colonial es hecha por ellos y para ellos. Se trata de una cultura masculina. Las mujeres tienen dos posibilidades de acceder a la cultura superior: las órdenes religiosas y la corte, pero en ambas les está vedado hacer un uso público de su conocimiento: Sor Juana Inés de la Cruz va a ser un caso extraordinario en este contexto. "Pero el carácter acentuadamente masculino de la cultura novohispana es un hecho al que la mayoría de los biógrafos de Sor Juana no han dado su verdadera significación" ${ }^{\prime 1}$.

Otro rasgo de la cultura colonial es que se trata de una cultura verbal: el púlpito, la cátedra y la tertulia son sus focos de difusión. Casi nadie escribe, pero todo el mundo habla sin parar, diserta, conmina, advierte y recomienda. Quienes más escriben son los teólogos, pero repiten lo que otros - los Padres de la Iglesia o Aristóteles- 
han dicho. Asimismo, la crítica es prácticamente inexistente. Nadie está dispuesto a examinar los principios fundantes de la sociedad, sino que lo que se busca es defenderlos. Las tendencias críticas son combatidas con ferocidad por clérigos y filósofos, por no coincidir con los dogmas admitidos como verdades absolutas. "La animación intelectual, la pasión y el ingenio no deben ocultarnos el carácter esencialmente dogmático de la cultura. La crítica teológica y literaria, por más vivaz y docta que fuera, no era realmente crítica, en el sentido moderno de la palabra: examen de los principios y los fundamentos. La Universidad y la Iglesia eran las depositarias del saber codificado de la época, el saber lícito y no contaminado por la herejía. Guardiana de la ortodoxia, la Universidad no tenía por función examinar y discutir los principios que fundaban a la sociedad, sino defenderlos" ${ }^{32}$.

Como quiera que sea, en la sociedad colonial el saber se va asociando con el ejercicio del poder político hasta convertirse, con el paso del tiempo, en una de las tradiciones culturales latinoamericanas. Se trata de un influjo cultural que viene de España (es, pues, europeo), sólo que la tríada hispánica-medieval es religión-saber-poder, mientras que los criollos ilustrados intentan renunciar al eje religioso, pero mantienen firme el vínculo saber-política, que va a ser una constante en la historia latinoamericana (como ideal político) hasta los años 90 del siglo XX. La influencia del marxismo - un pensamiento fuertemente religioso ${ }^{33}$ - va a reforzar esta imbricación saber-política, con aquello de que la verdad de una idea se determina por su eficacia política, es decir, por su capacidad transformadora, tal como lo acota Marx en sus célebres Tesis sobre Feuerbach. De este modo, los intelectuales de la izquierda latinoamericana en el siglo $\mathrm{XX}$ van a estar a tono con la tradición novohispana que primero vincula religión, saber y política y que luego intenta desmarcar a estas dos últimas de aquélla, aunque sin lograrlo totalmente.

Ahora bien, la modernidad europea ya desde el renacimiento apunta hacia una separación (hacia una autonomización) entre saber, política y religión: en esto consiste el proceso de secularización, tal como fue conceptualizado por Max Weber. No quiere decir que entre esos tres ámbitos no se den cruces, pero lo característico es que se convierten en prácricas autónomas o que necesitan de mediaciones para relacionarse: por ejemplo, el saber necesita de la técnica para concretarse en política o la religión necesita de "negociadores" para incidir en la polí- 
tica, pero tiende a operarse una separación entre las actividades específicamente clericales y las específicamente políticas, o entre las actividades específicamente científicas (o filosóficas) y las políticas (o religiosas). La forma más clara de ver esto es el surgimiento de "especialistas" en cada esfera de actividad: los políticos, los científicos, los filósofos y los sacerdotes. Weber examina con singular agudeza las "vocaciones" del científico y del político en la modernidad, lo cual ilumina la discusión que estamos haciendo en este punto. "En nuestros días - dice Weber - la ciencia es una 'profesión' especializada al servicio del conocimiento de sí mismo y del conocimiento de las relaciones objetivas. No es una merced de los profetas que nos ofrecen sus auxilios y nos comunican sus revelaciones, ni tampoco un elemento más en la reflexión de sabios y filósofos que meditan sobre el sentido de la existencia" ${ }^{34}$. Sobre el político "profesional" -o sobre la política como profesión- dice Weber lo siguiente: "son dos las figuras clásicas del liderazgo que aparecen en todas las regiones del mundo y en todas las épocas históricas: el mago y el profeta, por un lado; el soberano guerrero, el jefe de una cuadrilla de bandidos, el condottiere, por otro. Sin embargo, Occidente cuenta con otra figura característica que sin duda nos es más cercana: el líder político que surgió primero con el 'demagogo' libre de las ciudades-estado de Occidente y, sobre todo, de las culturas de los países del interior de Europa, y luego con el 'lider del partido' parlamentario, tan arraigado en los estados constitucionales de Occidente. Estos políticos... deben su posición a la 'profesión', en el sentido más estricto de la palabra"3s.

A diferencia de lo que sucede en la modernidad europea, en la sociedad colonial (en continuidad con el orden español) no hay "especialistas", porque personas concretas - una persona- busca concentrar el saber, el poder (militar y político) y la autoridad religiosa: esta es la matriz del caudillo que tanta presencia va a tener en la historia latinoamericana. Los criollos ilustrados se mueven en el mismo esquema: intentan poner entre paréntesis la religión, pero mantienen la vinculación saber-política; y las grandes personalidades intelectuales latinoamericanas en el siglo XIX y XX, quizás hasta Octavio $\mathrm{Paz}$, se mueven en ese esquema. Son personalidades únicas que no sólo saben, sino que quieren dictar y ejecutar — desde ese saberdeterminadas formas de organizar la sociedad. Esta imbricación de saber y poder en una persona es peculiar a América Latina: los dicta- 
dores, al estilo de Fidel Castro, quieren también ser reconocidos -y legitimarse - como intelectuales y de allí la profusión de obras escritas - discursos, entrevistas, memorias y ensayos- que suele ir aparejada con su labor política.

En definitiva, y volviendo al tema específico de la cultura colonial, hay que decir que se trata de una cultura cerrada sobre sí misma con la que se protege a una sociedad también cerrada sobre sí misma, imposibilitada para cambiar y transformarse. Es una cultura a la medida de una sociedad -la colonial-; hecha para durar y que para tal fin se alimenta de un humus religioso que da sentido y orienta la vida de sus miembros.

A este respecto, Paz dice lo siguiente: "la sociedad colonial es un orden hecho para durar. Quiero decir, una sociedad regida conforme a principios jurídicos, económicos y religiosos plenamente coherentes entre sí y que establecían una relación viva y armónica entre las partes y el todo. Un mundo suficiente, cerrado al exterior, pero abierto a lo ultraterreno... El catolicismo es el centro de la sociedad colonial porque de verdad es la fuente de vida que nutre las actividades, las pasiones, las virtudes y hasta los pecados de siervos y señores, de funcionarios y sacerdotes, de comerciantes y militares. Gracias a la religión, el orden colonial no es una mera superposición de nuevas formas históricas, sino un organismo viviente ${ }^{36}$. Se trata de un orden cerrado sobre sí mismo y cerrado al porvenir: un orden inmóvil y opuesto al cambio. Es esta rigidez del orden colonial lo que explica su derrumbe relativamente fácil durante el primer cuarto del siglo XIX.

Fue ese mundo cultural en donde Sor Juana dio a luz a su obra poética y filosófica. Dado que este ensayo tiene como propósito indagar acerca de sus ideas filosóficas, las preguntas que se imponen son las siguientes: ¿cuáles son sus ideas filosóficas? ¿Cuáles son los temas y problemas filosóficos que fueron objeto de sus preocupaciones? ¿Dónde y cómo aparecen esos temas y problemas? Estas son las preguntas que nos ocuparán en lo que sigue a continuación.

\section{Las ideas filosóficas de Sor Juana}

Entre los estudiosos de Sor Juana que se han preocupado por su pensamiento existe el consenso de que en el poema "Primero sueño", la Carta Atenagórica y la Respuesta a Sor Filotea de la Cruz se encuen- 
tran las ideas filosóficas (y teológicas) más elaboradas de la poetisa mexicana. En seguida, nos ocuparemos de esos textos que, efectivamente, nos permitirán tener una visión más cabal del lugar de Sor Juana en la historia de la filosofía latinoamericana. Antes de eso, sin embargo, es oportuno dejar anotado que las preocupaciones filosóficas de Sor Juana no aparecen solamente en los textos referidos, sino que están dispersas en varios de sus poemas. Lamentablemente, los límites de este ensayo no permiten hacer el rastreo de tales preocupàciones en el conjunto de la producción poética de la monja mexicana. Aquí nos conformamos, sólo a modo de ejemplo, con citar algunos versos de sus romances filosóficos y amorosos que sirven para ilustrar su capacidad de poetización filosófica.

\section{ROMANCES FILOSÓFICOS Y AMOROSOS (FRAGMENTOS) $^{37}$}

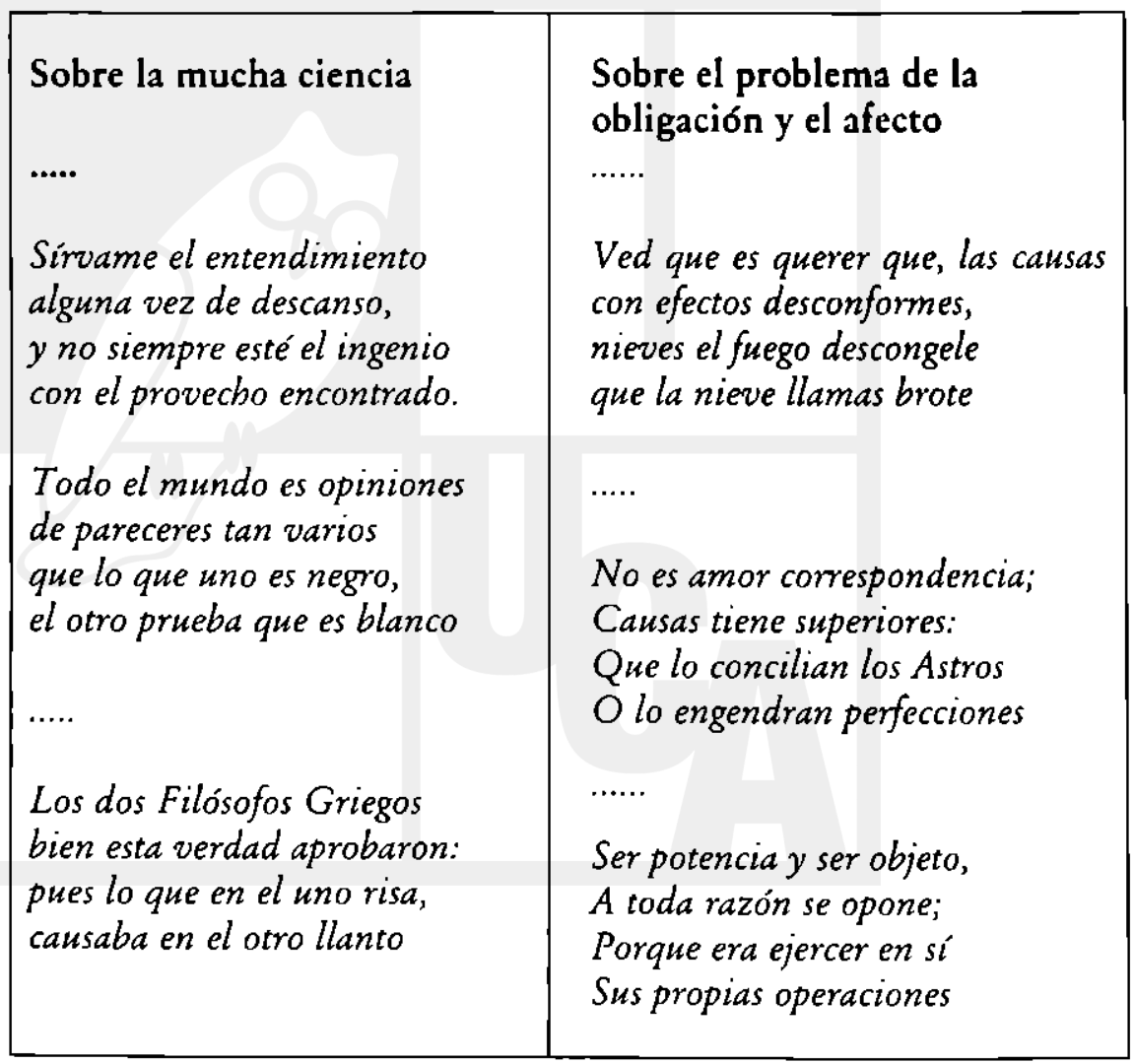


Para todo se balla prueba $y$ razón en que fundarlo; $y$ no bay razón para nada, de baber razón para tanto

1Qué feliz es la ignorancia del que, indoctamente sabio, balla de lo que padece, en lo que ignora, sagrado!

También es vicio el saber: que si no se va atajando, cuando menos se conoce es más nocivo el estrago.

....

Aprendamos a ignorar, Pensamiento, pues ballamos Que cuanto añado al discurso, tanto le usurpo a los años.
A parte rei se distingue El objeto que conoce; $Y$ lo amable, no lo amante, Es blanco en sus arpones

Amor no busca la paga de voluntades conformes, que tan bajo interés fuera indigna usura de los dioses.

No bay cualidad que él pueda imprimir alteraciones, del bielo de los desdenes, del fuego de los favores.

Su sér es inaccesibleal discurso de los hombres, que aunque el efecto se sienta la esencia no se conoce.

Con todo, como ya señalamos, es en el poema "Primero sueño", en el que Sor Juana muestra lo mejor de su talante filosófico. Escrito aproximadamente en 1685, es un poema de una composición compleja, comenzando por su longitud: 975 versos. A lo largo de ellos, se explora una aventura: la aventura del alma humana en búsqueda de conocimiento. Esa búsqueda sucede en el sueño de la poetisa: su cuerpo cae en un pesado dormir, el alma se desprende penosamente del cuerpo y asciende hacia la contemplación de la verdad. Al acercarse a la esfera superior, el alma tiene una visión intensa y luminosa que la deslumbra y ciega. Intenta ascender de nuevo, esta vez siguiendo un 
orden, pero fracasa. A la ascensión frustrada sigue el despertar: el cerebro despierta y, con él, despiertan los sentidos y los miembros. Sale el sol y la poeta despierta: todo termina en una no visión. "En Primero sueño -escribe Octavio Paz - nos cuenta cómo, mientras dormía el cuerpo, el alma ascendió a la esfera superior; allá tuvo una visión de tal modo intensa, vasta y luminosa, que la deslumbró y la cegó; repuesta de su ofuscamiento, quiso subir de nuevo, ahora peldaño a peldaño, pero no pudo; cuando dudaba sobre qué otro camino tomar, salió el Sol y el cuerpo despertó. El poema es el relato de una visión espiritual que termina en una no-visión"3.

José Gaos estudió detenidamente el poema y una de sus conclusiones más relevantes fue la siguiente: "el poema tiene solamente cinco partes: la media noche, el dormir, el sueño, el despertar, el amanecer. Se trata de una composición de una simetría perfecta en torno a un centro: en los extremos, la media noche y el amanecer; el dormir y el despertar, entre los extremos y el centro; en éste, el sueño. Esta estructura resulta reforzada por el número de versos de las cinco partes: 150 la noche, 115 el dormir, 560 el sueño, 59 el despertar, 89 el amanecer. Las descripciones de la noche y del dormir son, sobre poco más o menos, [el] doble de largas que las del amanecer y el despertar, respectivamente; pero la de la noche guarda con la del amanecer una proporción muy cercana a la del dormir con la del despertar"39.

Es una lástima que por motivos de espacio no podamos transcribir todo el poema, sino apenas unos cuantos fragmentos, en los cuales se condensan, eso sí, las preocupaciones filosóficas de las que el mismo es expresión. Ordenaremos los fragmentos según el proceso que va del dormir de la poeta, su soñar, el deslumbramiento de su alma ante la luz, la reflexión de la pocta en su sueño, hasta su despertar.

PRIMERO SUEÑO

(FRAGMENTOS)

\begin{tabular}{|l|l|}
\hline Primer fragmento: el dormir & Fragmento dos: el soñar \\
E.... & El viento sosegado, el can domido, \\
éste yace, aquél quedo & \multicolumn{1}{|c|}{ El alma, pues, suspensa } \\
los átomos no mueve, & del exterior gobierno, -en que ocupada \\
con el susuro bacer temiendo leve, & en material empleo, \\
aunque poco, sacrilego ruido, & o bien o mal da el dia por gastado--, \\
violador del silencio sosegado. & solamente dispensa \\
\hline
\end{tabular}


El mar, no ya alterado,

ni aun la instable mecía

cerúlea cuna donde el Sol dormia;

$y$ los dormidos, siempre mudos, peces,

en los lechos lamosos

de sus obscuros senos cavemosos, mudos eran dos veces;

$y$ entre ellos, la engañosa

Alcione, a los que antes

(encantadora

en peces transformó, simples

transformada también, vengaba

[amantes, 'abora.

El sueño todo, en fin, lo poseía; todo, en fin, el silencio lo ocupaba: aun el ladrón dormia; aun el amante no se desvelaba.

El conticinio casi ya pasando iba, y la sombra dimidiaba, cuando de las diumas tareas fatigados, $-y$ no sólo oprimidos

\section{del afán ponderoso}

del corporal trabajo, mas cansados del deleite también que también

objeto continuado a los sentidos aun siendo deleitoso:

que la Naturaleza siempre alterna ya una, ya otra balanza, distribuyendo varios ejercicios, ya al ocio, ya al trabajo destinados, en el fiel infiel con que gobiema la aparatosa máquina del mundo)-; así, pues, de profundo sueño dulce los miembros ocupados, quedaron los sentidos del que ejercicio tienen ordinario, - trabajo en fin, pero trabajo amado remota, si del todo separada no, a los de muerte temporal opresos lánguidos miembros, sosegados buesos, los gajes del calor vegetativo, el cuerpo siendo, en sosegada calma, un cadáver con alma, muerto a la vida y a la muerte vivo, de lo segundo dando tardas señas el del reloj humano vital volante que, si no con mano, con arterial concierto, unas pequeñas muestras, pulsando, manifiesta lento de su bien regulado movimiento.

A la región primera de su altura, (infima parte, digo, dividiendo en tres su continuado cuerpo borrendo), el rápido no pudo, el veloz vuelo del águila - que puntas bace al Cielo $y$ al Sol bebe los rayos pretendiendo entre sus luces colocar su nidollegar; bien que esforzando más que nunca el impulso, ya

las dos plumadas velas, ya peinando con las garras el aire, ha pretendido, tejiendo de los átomos escalas, que su inmunidad rompan sus dos lalas.

seguin de Homero, digo, la [sentencia,

las Pirámides fueron materiales tipos solos, señales exteriores de las que, dimensiones interiores, especies son del Alma intencionales: que como sube en piramidal punta al Cielo la ambiciosa llama ardiente, asi la bumana mente su figura trasunta, 
si hay amable trabajo--,

si privados no, al menos suspendidos, $y$ cediendo al retrato del contrario de la vida, que--lentamente amado-cobarde embiste y vence perezoso con armas soñolientas, desde el cayado humilde al

sin que haya distintivo [cetro altivo, que el sayal de la púrpura disciema: pues su nivel, en todo poderoso, graduia por exentas a ningunas personas, desde la de a quien tres forman soberana tiara, hasta la que pajiza vive choza; desde la que el Danubio undoso dora, a la que junco bumilde, bumilde mora;

$y$ con siempre igual vara

(como, en efecto, imagen poderosa de la muerte) Morfeo el sayal mide igual con el brocado. y a la Causa Primera siempre aspira, --céntrico punto donde recta tira la linea, si ya no circunferencia, que contiene, infinita, toda esencia--.

éstos, pues, Montes dos artificiales (bien maravillas, bien milagros sean),

y aun aquella blasfema altiva Torre de quien hoy dolorosas son señales --no en piedras, sino en lenguas [desiguales, porque voraz el tiempo no las borre-los idiomas diversos que escasean el sociable trato de las gentes (haciendo que parezcan diferentes los que unos hizo la Naturaleza, de la lengua por sólo la extrañeza), si fueran comparados a la mental pirámide elevada donde, sin saber cómo, colocada el Alma se miró, tan atrasados se hallaran, que cualquiera gradüara su cima por Esfera: pues su ambicioso anbelo, baciendo cumbre de su propio vuelo, en la más eminente la encumbró parte de su propia mente, de sí tan remontada, que creía que a otra nueva región de si salia. 
Fragmento tres: el deslumbramiento

Tanto no, del osado presupuesto, revocó la intención, arrepentida, la vista que intentó descomedida en vano bacer alarde contra objeto que excede en

las lineas visuales, excelencia - contra el Sol, digo, cuerpo cuyos rayos castigo son fogoso, que fuerzas desiguales despreciando, castigan rayo a rayo el confiado, antes atrevido y ya llorado ensayo, (necia experiencia que costosa tanto fue, que Ícaro ya, su propio llanto lo anegó entemecido)-, como el entendimiento, aqui

no menos de la inmensa [vencido Imuchedumbre (de tanta maquinosa pesadumbre de diversas especies, conglobado esférico compuesto), que de las cualidades de cada cual, cedio;

Mas como al que ba usurpado diutuma obscuridad, de los objetos visibles los colores, si súbitos le asaltan resplandores, con la sobra de luz queda más ciego - que el exceso contrarios bace

en la torpe potencia, que la lumbre del Sol admitir luego no puede por la falta de costumbre-, y a la tiniebla misma, que antes era
Fragmento cuatro: la reflexión de la poeta en su sueño

en las que artificiosas dos veces cinco son Categorias:

reducción metafísica que enseña (los entes concibiendo generales en sólo unas mentales fantasias donde de la materia se desdeña el discurso abstraido)

ciencia a formar de los universales, reparando, advertido, con el arte el defecto de no poder con un intüitivo conocer acto todo lo crïado, sino que, baciendo escala, de un en otro va ascendiendo grado a [concepto $y$ el de comprender orden relativo sigue, necesitado del entendimiento limitado vigor, que a sucesivo discurso fía su aprovechamiento...

De esta serie seguir mi

el método queria, [entendimiento o del infimo grado del ser inanimado (menos favorecido, si no más desvalido, de la segunda causa productiva), pasar a la más noble jerarquia que, en vegetable aliento, primogénito es, aunque grosero, de Thetis, -el primero que a sus fertiles pechos maternales, con virtud atractiva, 
tenebroso a la vista impedimento, de los agravios de la luz apela, y una vez $y$ otra con la mano cela de los débiles ojos deslumbrados los rayos vacilantes, sirviendo ya - piadosa medianerala sombra de instrumento para que recobrados por grados se babiliten, porque después constantes su operación más firmes ejerciten ique asi del mal el bien tal vez se no de otra suerte el Alma, que [saca!-:

de la vista quedó de objeto tanto, la atención recogió, que derramada en diversidad tanta, aun no sabia recobrarse a si misma del espanto que portentoso babia su discurso calmado, permitiéndole apenas de un concepto confuso el informe embrión que, mal

inordinado caos retrataba (formado, de confusas especies que abrazaba, - sin orden avenidas, sin orden separadas, que cuanto más se implican [combinadas tanto más se disuelven desunidas, de diversidad llenas-. ciñendo con violencia lo difuso de objeto tanto, a tan pequeño vaso, (aun al más bajo, aun al menor, escaso). los dulces apoyó manantiales de bumor terrestre, que a su Inutrimento natural es dulcísimo alimento-, $y$ de cuatro adomada operaciones de contrarias acciones, ya atrae, ya segrega diligente lo que no serle juzga conveniente, ya lo superfluo expele, y de la copia la substancia más útil bace propia; .... $y$ de este corporal conocimiento baciendo, bien que escaso, al supremo pasar maravilloso compuesto triplicado, de tres acordes lineas ordenado $y$ de las formas todas inferiores compendio misterioso:

bisagra engarzadora de la que más se eleva entronizada Naturaleza pura $y$ de la que, criatura menos noble, se ve más abatida: no de las cinco solas adomada sensibles facultades, mas de las interiores que tres rectrices son, ennoblecida, -que para ser señora de las demás, no en vano la adomó Sabia Poderosa Mano- ...

Estos, pues, grados discumir quería unas veces; pero otras, disentia, excesivo juzgando atrevimiento el discurrirlo todo, quien aun la más pequeña, aun la más fácil parte no entendia de los más manüales efectos naturales

.... 


\begin{tabular}{|c|c|}
\hline & $\begin{array}{l}\text { Pues si a un objeto solo, -repetia } \\
\text { tímido el Pensamiento-, } \\
\text { buye el conocimiento } \\
\text { y cobarde el discurso se desvia; } \\
\text { si a especie segregada } \\
\text { - como de las demás independiente, } \\
\text { como sin relación considerada- } \\
\text { da las espaldas el entendimiento, } \\
\text { y asombrado el discurso se espeluza } \\
\text { del dificil certamen que rehúsa } \\
\text { acometer valiente, } \\
\text { porque teme cobarde } \\
\text { comprebenderlo o mal, o nunca, o } \\
\text { tarde, } \\
\text { ¿cómo en tan espantosa } \\
\text { máquina inmensa discurrir pudiera, } \\
\text { cuyo terrible incomportable peso } \\
\text {-si ya en su centro mismo no estri- } \\
\text { bara- } \\
\text { de Atlante a las espaldas agobiara, } \\
\text { de Alcides a las fuerzas excediera; } \\
\text { y el que fue de la Esfera } \\
\text { bastante contrapeso, } \\
\text { pesada menos, menos ponderosa } \\
\text { su máquina juzgara, que la empresa } \\
\text { de investigar a la Naturaleza? }\end{array}$ \\
\hline
\end{tabular}


Fragmento cinco: el comienzo del despertar

las cadenas del sueño desataban:

$y$ la falta sintiendo de alimento

los miembros extenuados,

del descanso cansados,

ni del todo despiertos ni dormidos,

muestras de apetecer el movimiento

con tardos esperezos

ya daban, extendiendo

los nervios, poco a poco, entumecidos, $y$ los cansados buesos

(aun sin entero arbitrio de su dueño)

volviendo al otro lado--,

a cobrar empezaron los sentidos,

dulcemente impedidos

del natural beleño,

su operacion, los ojos entreabriendo.

$Y$ del cerebro, ya desocupado,

las fantasmas buyeron

$y$--como de vapor leve formadas--

en fácil humo, en viento convertidas,

su forma resolvieron.

En tanto el Padre de la Luz

de acercarse al Oriente [ardiente,

ya el término prefijo conocía,

y al antípoda opuesta despedia

con transmontantes rayos:

que - de sh luz en trémulos

en el punto bace mismo su

desmayas-

que nuestro Oriente ilustra

Occidente,

Pero de Venus, antes, el bermoso luminoso.

apacible lucero

rompió el albor primero,

$y$ del viejo Tithón la bella esposa
Fragmento seis: el despertar de la poeta

Llegó, en efecto, el Sol cerrando el

giro

que esculpió de oro sobre azul zafira: de mil multiplicados

mil veces puntos, flujos mil dorados

- lineas, digo, de luz clara-, salian

de su circunferencia luminosa,

pautando al Cielo la cerúlea plana;

y a la que antes funesta fue tirana

de su imperio, atropadas embestian: que sin concierto huyendo presurosa -en sus mismos barrores trapezandosu sombra iba pisando,

y llegar al Ocaso pretendia con el (sin orden ya) desbaratado ejército de sombras, acosado de la luz que el alcance le seguía.

Consiguio, al fin, la vista del

el fugitivo paso,

IOcaso

$y$-en su mismo despeño recobrada esforzando el aliento en la rüina-, en la mitad del globo que ba dejado el Sol desamparada, segunda vez rebelde determina mirarse coronada, mientras nuestro Hemisferio la

ilustraba del Sol madeja hermosa, [dorada que con luz judiciosa de orden distributiva, repartiendo a las cosas visibles sus colores $i b a, y$ restituyendo entera a los sentidos exteriores su operación, quedando a luz más [cierta el mundo iluminado y yo despierta: 
- amazona de luces mil vestida,

contra la noche armada,

bermosa si atrevida,

valiente aunque llorosa-,

su frente mostro bermosa

de matutinas luces coronada...

Como ya dijimos, "Primero sueño" trata del soñar del alma. ¿Soñar para qué? Para conocer. ¿Conocer qué? La causa última de las cosas. ¿Por qué soñar para conocer la causa última de las cosas? Porque en el sueño el alma se separa del cuerpo y, así, liberada de éste, puede recorrer el camino que la lleve, paso a paso, de lo sensible hasta la suprasensible, de la oscuridad a la luz. De esta manera, Sor Juana reflexiona sobre un problema filosófico de primera importancia: ¿cómo pueden los humanos - si eso es posible- acceder al conocimiento último de la realidad.

Para responder esa pregunta, Sor Juana se vale de la tradición aristotélica - que aparece en su reflexión sobre el orden de la Naturaleza y el orden del Conocimiento-, hermética -presente en el relato del viaje del alma una vez que el cuerpo se ha dormido" y neoplatónica en que ella se había educado. Hay que recordar que en el neoplatonismo, así como en la tradición hermética, el tema de la unión alma-cuerpo fue algo de primera importancia, al igual que lo fue el tema de la separación del alma respecto del cuerpo, si la primera quería acceder al conocimiento verdadero. La separación definitiva sólo se da en la muerte, pero cuando los hombres todavía viven la misma se puede dar en situaciones excepcionales, por ejemplo en el sueño o en el éxtasis ${ }^{42}$. "El fundamento de esta creencia - comenta Paz- es un dualismo estricto (atemperado por Aristóteles y después por la escolástica): el alma, por ser de naturaleza distinta al cuerpo, puede separarse de su envoltura carnal en momentos excepcionales, como el éxtasis y ciertos sueños. Las visiones son esas realidades supralunares que el alma ve en su viaje espiritual"13.

Sor Juana no sólo domina esas tradiciones intelectuales, sino que las explota creativamente, lo cual le permite anticipar algunas de las problemáticas filosóficas modernas. En primer lugar, el alma que viaja en búsqueda del conocimiento es el alma solitaria que se ve enfrenta- 
da, sola, con el universo. Sor Juana da inicio, dice Paz, a "una actitud -la confrontación del alma solitaria con el universo- que más tarde, desde el romanticismo, será el eje espiritual de la poesía de Occidente" "14. En segundo lugar, el escepticismo acerca de lo que efectivamente podemos conocer. Sor Juana rompe con la tesis vigente en su época de que, si seguía el método correcto, se podía conocer con certeza lo que eran las causas últimas de las cosas. Más aun, Sor Juana somete a una dura crítica esa tesis; y su conclusión es desoladora, pero muy moderna: el afán de conocer lo último de la realidad del alma humana está condenado al fracaso. Esta conclusión es también una confesión: Sor Juana confiesa su propio fracaso intelectual. "La idea de que el saber es imposible - dice Paz- se bifurca en dos: el hombre no puede conocer por ser hombre o por alguna circunstancia determinada. Por ejemplo, en el caso de Sor Juana, por ser Sor Juana"45. Y José Gaos remata: "la intención de la poetisa es inequívoca, indisputablemente patente: dar expresión poética a la experiencia capital de su vida: la del fracaso de su afán de saber, del que había orientado su vida toda, la vida de ella, Juana de Asbaje, desde la infancia, desde antes de la entrada en religión, a través de ésta, a lo largo de toda su vida hasta entonces, el momento ya precrítico, sino resueltamente crítico, de composición del poema"16. Es por eso que para Gaos lo que narra el poema "Primero sueño" es el "fracaso de un sueño": el sueño de conocer.

Finalmente, Sor Juana actualiza una pasión que se había perdido ante el predominio de la frialdad y la rigidez racional de la filosofía neoescolástica: el amor al saber, pero un amor apasionado. "Con "Primero sueño" -reconoce Paz- aparece una pasión nueva en la historia de nuestra poesía: el amor al saber. Me explico: la pasión, claro, no era nueva; lo nuevo fue que Sor Juana la convirtiese en un tema poético y que la presentase con la violencia y la fatalidad del erotismo. Para ella la pasión intelectual no es menos fuerte que el amor a la gloria. La pasión intelectual -la razón- alista el ánimo, en la mejor tradición platónica, para que la acompañe en su aventura. Y aquí surge otra y mayor diferencia con la tradición: si el conocimiento parece imposible, hay que burlar al hado y atreverse" ${ }^{17}$. Sor Juana se atrevió: usó la tradición de la que era heredera para mostrar sus limitaciones. Usó el saber establecido para mostrar que el saber verdadero es imposible, porque, en definitiva, como dice Gaos, "el afán de saber es un sueño". 
En 1690, cinco años después de haber publicado "Primero sueño", Sor Juana escribe la Carta Atenagórica en la que critica un "sermón del mandato" predicado por el jesuita Antonio Vieyra. En este texto, Sor Juana opone, a lo que Vieyra considera las mayores "finezas" de Cristo a los hombres, su propia concepción de lo que es la mayor fineza de Dios, en la cual es clara su apuesta por la libertad humana. "Como hablamos de finezas —escribe Sor Juana-, dije yo que la mayor fineza de Dios, en mi sentir, eran los beneficios negativos; esto es, los beneficios que Dios nos deja de hacer porque sabe lo mal que le hemos correspondido... La mayor fineza del Divino Amor, en mi sentir, son los beneficios que nos deja de hacer por nuestra ingratitud... Luego, según nuestro modo de concebir, más le cuesta a Dios el no hacernos beneficios que el hacérnoslos y, por consiguiente, mayor fineza es el suspenderlos que el ejecutarlos... Luego es mayor beneficio el no hacerle beneficios. iAh, Señor y Dios mío, qué torpes y ciegos andamos cuando no os reconocemos esta especie de beneficio negativo que nos hacéis! $!^{n / 8}$.

La mayor fineza de Dios, pues, es no hacer nada por el hombre, es decir, dejarlo en libertad. ¿Libertad para qué? En el caso de Sor Juana, libertad para conocer. "En una monja amante de la poesía y de la ciencia, más preocupada por el saber que por el salvarse -escribe Octavio Paz-, esta idea corría el riesgo de ser juzgada como algo más que una sutileza teológica. Al afirmar que las mayores finezas divinas son negativas, ¿no defendía indirectamente su afición al saber profano frente a todos los que le incitaban a dejar los estudios de la tierra por los del cielo? Considerar como favor la indiferencia divina significaba, por otra parte, extender la esfera del libre albedrío. El don más alto de Dios consistía en abandonar los hombres a su suerte"19.

El Obispo de Puebla, Manuel Fernández de Santa Cruz, se hace cargo del desafío crítico lanzado por Sor Juana y escribe, bajo el nombre de "Sor Filotea", su Carta de Sor Filotea de la Cruz, en la que, como dice Beatriz Colombi, hace una "reconvención, una demarcación de los límites respecto de qué puede saber, qué puede decir y qué puede hacer una monja en el contexto de la Colonia novohispana. La carta del Obispo puede ser leída como un tratado de conducta, un manual de comportamientos, que demuestra la administración de un saber y la gobernabilidad de un sujeto: el femenino colonial"so. 
Letras que engendran elación - dice en su carta Sor Filotea-, no las quiere Dios en la mujer, pero no las reprueba el Apóstol [San Pablo] cuando no sacan a la mujer del estado de obediente. Notorio es a todos que el estudio y saber han contenido a V.md. en el estado de súbdita, y que la ban servido de perfeccionar primores de obediente; pues si las demás religiosas por la obediencia sacrifican la voluntad, V.md. cautiva el entendimiento, que es el más arduo y agradable bolocausto que puede ofrecerse en las aras de la Religión.

No pretendo, según este dictamen, que V.md. mude el genio renunciando los libros, sino que le mejore, leyendo alguna vez el de Jesucristo. Ninguno de los evangelistas llamó libro a la genealogía de Cristo, si no es San Mateo, porque en su conversión no quiso este Señor mudarle la inclinación, sino mejorarla, para que si antes, cuando publicano, se ocupaba en libros de su trato e intereses, cuando el apóstol mejorarse el genio, mudando los libros de su ruina en el libro de Jesucristo. Mucho tiempo ha gasto V.md. en el estudio de filósofos $y$ poetas; ya será razón que se perfeccionen los empleos y que se mejoren los libros".

En otras palabras, Fernández de Santa Cruz manda a Sor Juana a que se ocupe menos de la filosofía y la poesía y más de la fe y la religión. Es claro que esta amonestación del Obispo de Puebla es una reacción a la tesis planteada por Sor Juana en la Carta Atenagórica, porque, como insiste Sor Filotea (es decir, Fernández de Santa Cruz) al final de su carta, "estoy muy cierta y segura de que si V.md., con los discursos vivos de su entendimiento, formase y pintase una idea de las perfecciones divinas (...), al mismo tiempo se vería ilustrada de luces su alma y abrasada su voluntad y dulcemente herida de amor de su Dios, para que este Señor, que ha llovido tan abundantemente beneficios positivos en lo natural sobre vuestra V.md., no se vea obligado a concederle beneficios solamente negativos en lo sobrenatural; que por más que la discreción de V.md. les llama finezas, yo les tengo por castigos: porque sólo es beneficio el que Dios hace al carazón humano previniéndole con su gracia para que le corresponda agradecido, disponiéndole con un beneficio reconocido, para que no represada, la liberalidad divina se los haga mayores" ${ }^{25}$.

Son Juana, en su Respuesta a Sor Filotea de la Cruz —su último escrito-, defiende su derecho al saber, al tiempo que confiesa, al igual que lo hizo en "Primero sueño", los límites de todo saber huma- 
no. De entrada, Sor Juana dice a Sor Filotea que lo primero que se le ocurrió era no responder a su carta: "perdonad Señora mía, la digresión que me arrebató la fuerza de la verdad; y si la he de confesar toda, también es buscar efugios para huir de la dificultad de responder, y casi me he determinado a dejarlo al silencio; pero como este es cosa negativa, aunque explica mucho con el énfasis de no explicar, es necesario ponerle algún breve rótulo para que se entienda lo que se pretende que el silencio diga; y si no, dirá nada el silencio, porque es ese su propio decir: decir nada"53. Cuando termine de escribir su carta, Sor Juana tomará la decisión de callar para siempre, es decir, de sumergirse en el silencio que dice nada. Sin embargo, antes de callar para siempre, Sor Juana dice lo que ha sido la razón de su vida entera:

Lo que sí es verdad que no negaré -escribe Sor Juana- (lo uno porque es notorio a todos, y lo otro porque, aunque se contra mi, me ha becho Dios la merced de darme grandísimo amor por la verdad) que desde que me rayó la primera luz de la razón, fue tan vebemente $y$ poderosa la inclinación a las letras, que ni ajenas represiones-que be tenido muchas-, ni propias reflejas -que be becho no pocas-, han bastado para que deje de seguir este natural impulso que Dios puso en $m i^{s 4}$.

Este don, prosigue Sor Juana, la llevó a internarse en los terrenos de las ciencias - la lógica, la física, la aritmética, la retórica-, conciente de que ese camino era necesario para acceder a la cumbre de la sagrada teología. Recorrió este camino porque se sabía ignorante, "pues si conociera, como debo, esto mismo no escribiera"s5. No se sintió culpable por hacer algo que se consideraba meritorio sólo cuando era obra de hombres; sin embargo, estuvo dispuesta a someterse a la autoridad: "si son culpa, por la misma razón creo que no la he tenido: más, con todo, vivo siempre tan desconfiada de mí, que ni en esto ni en otra cosa me fío del juicio; y así remito la decisión a ese soberano talento, sometiéndome luego a lo que sentenciare, pues esto no ha sido más que una simple narración de mi inclinación a las letras" La sentencia ya había sido dictada: según el Obispo de Puebla, Sor Juana debía abandonar la filosofía y la poesía y dedicarse a la fe y la religión. Ella prefirió el silencio. Como señala Octavio Paz, dos años después de la Respuesta a Sor Filotea de la Cruz, Sor Juana "vende sus libros y se abandona a los poderes del silencio. Madura para la muerte, no escapa a la epidemia de 1695 . Entre las pocas cosas que se 
encontraron en su celda figura un romance incompleto 'en reconocimiento a las inimitables plumas de la Europa que hicieron mayores sus obras con sus elogios'"57.

En resumen, en palabras de Octavio Paz, "el fin lamentable de Sor Juana no da otro sentido a su obra, como propusieron sus censores. Al contrario, su derrota cobra, gracias a su obra, una significación diferente: su luz ilumina. Sus escritos, en especial la Respuesta y Primero sueño, son el mejor remedio contra esa intoxicación moral que hace ver su fin y su humillación como un motivo edificante"58. Los censores de Sor Juana intentaron hacer creer que ella se había convertido, no que había sido forzada al silencio, pero no lo lograron: Sor Juana, pues, se libró de las "trampas de la fe".

\section{Reflexion final}

Sor Juana Inés de la Cruz no sólo fue una mujer valiente, sino una mujer con un talento intelectual poco común. Nació y vivió en América; además de conocer la tradición filosófica - y la tradición poética- hizo una reflexión filosófica - y una elaboración poética - original. No reflexionó filosóficamente sobre problemas concretos de Nueva España, pero sí abordó uno de los problemas universales de la filosofía: qué y cómo los bumanos podemos conocer. Su aporte intelectual nos obliga a plantearnos de nuevo la pregunta acerca de lo que significa ser un filósofo latinoamericano. Y es que, sin que estén claros los motivos, existe una tendencia a definir al filósofo latinoamericano como aquel pensador que reflexiona filosóficamente sobre problemas concretos de América Latina, con lo cual se propende a marginar a quienes, siendo latinoamericanos, han realizado (o realizan) una reflexión filosófica más universal, al interior o fuera de América Latina. La obra filosófica de Sor Juana obliga a revisar la noción de lo que significa ser filósofo latinoamericano; más aun, obliga a revisar el énfasis que se ha hecho sobre lo latinoamericano, a expensas de lo propiamente filosófico. Porque lo que debería de contar, más que la adscripción geográfica del pensamiento filosófico que se elabora, es su talante estrictamente filosófico. Y es precisamente desde consideraciones estrictamente filosóficas que el pensamiento de Sor Juana -principalmente, las reflexiones contenidas en "Primero sueño" y la Respuesta a Sor Filotea de la Cruz- reúne todos los requisitos para ser considerado tal. Por ser un pensamiento hecho en 
México y por una mexicana, es un pensamiento latinoamericano; nada más por eso. Su alcance y su hondura trascienden las fronteras americanas, porque trata de un problema humano universal: la posibilidad y los límites del conocimiento.

¿De cuántos autonombrados orgullosamente "filósofos latinoamericanos" se podría decir lo mismo? Quizás de muy pocos, especialmente si se toma en cuenta que el latinoamericanismo de muchos de ellos los llevó, sin darse cuenta, a convertirse en meros repetidores de fórmulas de la filosofía europea, destinadas a servir de respuesta ad hoc a problemas particulares, como la identidad latinoamericana, la cuestión social o la construcción de la nación. Al seguir esta lógica, se olvidaron de la filosofía y se convirtieron en ideólogos (del nacionalismo, la revolución o el socialismo): dieron vida, como dice Eduardo Nicol, a un pensamiento filosófico marginal ${ }^{59}$. Los más vociferantes y provincianos, se hicieron críticos furibundos del eurocentrismo de la filosofía occidental, lo cual los llevó a la búsqueda de un pensamiento latinoamericano propio... para lo cual se valieron, como no podía ser para menos, de la tan denostada tradición filosófica europea.

Mientras tanto, otros pensadores latinoamericanos - varios de ellos sin ser filósofos de profesión, como Octavio Paz, Alfonso Reyes o Jorge Luis Borges- se dedicaban a reflexionar con rigor filosófico sobre problemas humanos universales, que por serlo eran también problemas de los hombres latinoamericanos. Estos otros pensadores son los continuadores legítimos de Sor Juana Inés de la Cruz, la primera filósofa latinoamericana; todos ellos -y los que como ellos, en América Latina reflexionaron (y reflexionan) filosóficamente sobre problemas humanos universales- merecen un lugar de primera importancia en la historia de la filosofía latinoamericana, más que aquellos que, siendo nominalmente filósofos, no han hecho más que repetir fórmulas filosóficas tomadas acríticamente de la tradición europea o, peor aun, se han dedicado (y se dedican) a lanzar diatribas contra el eurocentrismo filosófico, ofreciendo a cambio un pensamiento sin raíces y falto de rigor conceptual.

San Salvador, 15 de octubre de 2003 
1. Una primera aproximación a las ideas filosóficas de Sor Juana Inés de la Cruz fue realizada por el autor en marco del curso "Historia de la Filosofía Latinoamericana" ofrecido, en el primer semestre de 2000, a los alumnos de la licenciatura en de Filosofía de la UCA. El presente artículo recoge algunas de las ideas desarrollas en esa oportunidad, así como otras exploradas en el curso ofrecido en el segundo semestre de 2003 a alumnos y profesores del departamento de Filosoffa de la Universidad de El Salvador.

2. Cfr., Hobsbawm, E., "Identidad". Revista Intemacional de Filosofia Poltatica, No. 3, mayo de 1994, pp. 5-17. Bodei, R., "El largo adiós a la identidad personal". Revista Intemacional de Filosofía Polttica, No. 2, noviembre de 1993, Pp. 5-20; Díaz Cruz, R., "Experiencias de la idencidad". Revista Intemacional de Filosofía Politica, No. 2, noviembre de 1993, pp.63-74.

3. Cfr., Robles, L., "El pensamiento filosófico en España". En Filosofla iberoamericana en la época del encuentro. Madrid, Trota, 1992, PP. 15-50; Abellán, J. L., “El pensamiento renacentista en España y América”. En Ibíd., pp. 155-192.

4. Florescano, E., Etnia, Estado y Nacion. Ensayo sobre las identidades colectivas en México. México, Aguilar, 1997, pp. 295-296.

5. En los 14 tomos de las Obras Completas de Octavio Paz, el lector interesado podrá encontrar las distintas incursiones de $\mathrm{Paz}$ en problemas estrictamente filosóficos -es decir, problemas últimos sobre el hombre, el conocimiento y la realidad_, abordados con rigor y originalidad filosófica. Sólo por poner un par de ejemplos, de este talante son dos de los ensayos recogidos en el tomo 10 de sus Obras Completas, el primero titulado "Un más allá erótico: Sade" en el que reivindica el carácter filosófico de la obra del "Divino Marqués", y el segundo titulado "Claude Lévi-Strauss o el nuevo festín de Esopo", en el que argumenta sobre la triple importancia de los escritos del antropólogo francés: antropológica, filosófica y estética. Cfr. Paz, O., Obras Completas. Ideas y costumbres II. Usos y símbolos. México, FCE, 1993.

6. En los 22 tomos de las obras completas de Alfonso Reyes se encuentran sus distintas elaboraciones filosóficas. Por ejemplo, el tomo XVI recoge los importantes estudios de Reyes dedicados a la religión y a la mitología griegas; en esos, el mexicano no sólo deja constancia de su erudición filosófica, sino también de su creatividad y dominio de los autores y temas abordados. Cfr., Reyes, A., Obras completas de Alfonso Reyes. XVI. Religión griega. Mitología griega. México, FCE, 1989.

7. Indirectamente, este aporte fue reconocido en 1951 por José M. Gallegos Rocaful en su trabajo "El pensamiento mexicano en los siglos XVI y XVII". Este último autor divide la historia de la producción filosófica en México en el siglo XVI en dos periodos: 1) los primeros 50 años de la colonia, en los que se elaboran estudios que abordan temas como la incorporación de los indios a la cultura española, los problemas jurídicos y de legitimidad del dominio de España sobre América, el choque entre las dos culturas, la naturaleza de los indios y las nuevas ideas de hombre; 2) la implantación de la filosofía escolástica y la mezcla de pensamiento medieval y renacentista escolástica y la mezcla de pensamiento medieval y renacentista. Para Gallegos Rocalul, el siglo XVII —en el cual hizo 
su aporte Sor Juana- fue de "tradición y reposo". Cfr., Osorio Romero, I., "Sobre la historia de la filosoffa novohispana". En Conquistar el eco. La paradoja de la conciencia criolla. México, UNAM, 1989, PP. 64-65.

8. Ibid.p. 65.

9. Ibid.

10. Antes, en 1951, Octavio Paz ya había apuntado algunas tesis acerca de la importancia filosofica de "Primero sueño". Cfr. Paz, O., "Homenaje a Sor Juana Inés de la Cruz en su Tercer Centenario (1651-1695) ${ }^{\circ}$. Sur, No. 206, diciembre de 1951, pp. 29-40.

11. Paz, O., Sor Juana Inés de la Cruz o las trampas de la fe. México, FCE, 1996, Pp. 13 y 15.

12. Paz, O., Sor Juana Inés de la Cruz o las trampas..., p. 100.

13. A la muerte de Isabel Ramírez, en 1688 , la hacienda fue administrada por su hija María. Por su parte, Josefa, la otra hija, se compró, con un préstamo sobre sus alhajas una hacienda en la región de Chalco. Cfr., Paz, O., Sor Juana Inés de la Cruz o las trampas..., p. 101.

14. Ibid.

15. Ibid.

16. Volberg, B., “La Décima Musa de México: celebremos el $\mathbf{3 5 0}$ aniversario de Sor Juana Inés de la Cruz la mayor poetisa de Américan. Caimén, noviembre de 2001, p. 1.

17. $\mathrm{Paz}, \mathrm{O}$., Sor Juana Inés de la Cruz o las trampas..., p. 131.

18. Ibid., p. 141.

19. Ibid., p. 147.

20. Ibid., p. 149.

21. Ibid., p. 157.

22. Ibid., pp. 158-159.

23. Ibid., p. 159.

24. Ibid., p. 178.

25. Ibid., p. 205.

26. Ibid., p. 353.

27. La edición de sus Obras Completas de la editorial Porrúa recoge en casi $\mathbf{9 0 0}$ páginas densas y de letra menuda su producción poética y en prosa. Cfr., Sor Juane Inés de la Cruz. Obras Completas. México, Porrúa, 1977.

28. Paz, O., Sor Juana Inés de la Cruz o las trampas..., p. 181.

29. Ibid., p. 68.

30. Ibid., pp. 42-43.

31, Ibid., p. 69.

32. Ibid.

33. Cfr. Bloch, E., El ateísmo en el cristianismo. Madrid, Taurus, 1968

33. Weber, M., El trabajo intelectual como profesión. Barcelona. Bruguera, 1983, p. 53.

35. Ibid., p. 68

36. Paz, O., El laberinto de la soledad. México, FCE, 1999, pp. 110-111.

37. Sor Juana Inés de la Cruz. Obras Completas. México, Porrúa, 1977, pp. 6-11,

38. Paz, O., Sor Juana Inés de la cruz o las trampas..., p. 482.

Las Ideas filosbificas de Sor Juana Inés de la Cruz 
39. Gaos, J., “El sueño de un sueño”. Historia mexicana, No. 1, julio-septiembre de 1960 , p. 54.

40. Sor Juana Inés de la Cruz. Obras Completas..., pp. 183-201.

41. Paz, O., Sor Juana Inés de la Cruz..., Pp. 479 y ss.

42. Cfr., Wilson, E., La filosofia en la edad media. Desde los origenes patristicos basta el fin del siglo XIV. Madrid, Gredos, 1995, pp. 73 y ss.

43. Paz, O., Sor Juana Inés de la Cruz..., p. 472.

44. Ibid., p. 482.

45. Ibid., p. 497.

46. Gaos, J., “El sueño de un sueño"..., p. 7-8.

47. Paz, O., Sor Juana Inés de la Cruz..., p. 504.

48. Sor Juana Inés de la Cruz, "Carta Atenagórica". En Sor Juana Inés de la Cruz. Obras Completas..., pp. 824-826.

49. Paz, O., "Homenaje a Sor Juana...", p. 1.

50. Colombi, B., "La respuesta y sus vestidos: tipos discursivos y redes de poder en la respuesta a Sor Filotea". Revista del Area Multidisciplinaria de Estudios de la Mujer, No. 2, Facultad de Filosofía y Letras. Universidad de Buenos Aires, 1996, p. 1.

51. "Carta de Sor Filotea de Cruz". The Sor Juana Inés de la Cruz Project, Dartmouth College, 2000.

52. Ibid., p. 3.

53 "Respuesta a Sor Filotea de la Cruz". En Sor Juana Inés de la Cruz. Obras Completas..., p. 828.

54. Ibid., p. 830.

55. Ibid., p. 841 .

56. Ibid., p. 839.

57. Paz, O., "Homenaje a Sor Juana Inés de la Cruz...", p. 1.

58. Paz, O., Sor Juana Inés de la Cruz o las trampas de la fe..., p. 630.

59. Cfr., Nicol, E., El problema de la filosofía hispánica. México, FCE, 1998, Pp. 41 y ss. 